\title{
Partial Response in an RRx-001- Primed Patient with Refractory Small-Cell Lung Cancer after a Third Introduction of Platinum Doublets
}

\author{
Corey A. Carter ${ }^{a} \quad$ Bryan Oronsky ${ }^{b}$ Scott Caroen $^{b} \quad$ Jan Scicinski ${ }^{b}$ \\ Aiste Degesys $^{a} \quad$ Pedro Cabrales $^{c} \quad$ Tony R. Reid $^{d} \quad$ Christina Brzezniak $^{a}$ \\ ${ }^{a}$ Walter Reed Medical Center, Bethesda, Md., ${ }^{b}$ EpicentRx, Inc., Mountain View, Calif., \\ 'Department of Bioengineering, University of California, La Jolla, Calif., and \\ dMoores Cancer Center, La Jolla, Calif., USA
}

\section{Key Words}

Partial response $\cdot$ RRx-001 $\cdot$ Refractory small-cell lung cancer $\cdot$ Platinum doublets

\begin{abstract}
Small-cell lung cancer (SCLC), initially exquisitely sensitive to first-line cisplatin/etoposide, invariably relapses and acquires a multidrug chemoresistant phenotype that generally renders retreatment with first-line therapy both futile and counterproductive. This report presents the case of a 77-year-old Caucasian male with extensive-stage refractory SCLC who was restarted on platinum doublets as part of a clinical trial called TRIPLE THREAT (NCT02489903) involving pretreatment with the epi-immunotherapeutic agent RRx-001, and who achieved a partial response after only 4 cycles. The patient had received a platinum drug twice before, in 2009 for a diagnosis of non-small-cell lung cancer (squamous cell carcinoma) and in 2015 for SCLC, suggesting that RRx-001 pretreatment may sensitize or resensitize refractory SCLC patients to first-line chemotherapy.

\section{Introduction}

Small-cell lung cancer (SCLC) is a particularly aggressive form of lung cancer characterized by rapid doubling time, high growth fraction, and early dissemination [1]. The staging system for the disease incorporates a binary classification: limited-stage SCLC is confined to

\section{KARGER}

Dr. Jan Scicinski

EpicentRx, Inc.

800 W El Camino Real, Suite 180

Mountain View, CA 94040 (USA)

E-Mail jscicinski@epicentrx.com 
Carter et al.: Partial Response in an RRx-001-Primed Patient with Refractory Small-Cell Lung Cancer after a Third Introduction of Platinum Doublets

one hemithorax while all other disease is categorized as extensive-stage SCLC [2]. Typically radio- and chemosensitive at the outset, the development of resistance even after initial response is practically a fait accompli for extensive-stage SCLC, usually within the first year from diagnosis [3]. The predicted probability of the efficacy of second-line chemotherapy is based on response to first-line treatment; 'sensitive' disease, that is relapse beyond 60 or 90 days after completion of first-line treatment, is associated with a better prognosis and survival outcome than 'refractory' disease, that is no response or relapse during ongoing firstline treatment, and 'resistant' disease, that is progression within 60 or 90 days following first-line response [4].

The topoisomerase I inhibitor topotecan is approved in the United States and European Union only for second-line therapy of sensitive SCLC [5], while the synthetic anthracycline amrubicin is approved in Japan [6]. For refractory or resistant SCLC, no standard therapy is available. The overall survival with topotecan in the resistant/refractory population ranges from 4.7 to 5.7 months [7] while the response rate is $<10 \%$ [8]. In addition to topotecan and amrubicin, cyclophosphamide, Adriamycin and vincristine (CAV) has been investigated with similarly poor overall survival, progression-free survival and response rates [9]. RRx-001 is a first-in-class systemically non-toxic [10] epi-immunotherapeutic agent [11] which possesses both radiosensitizing and chemosensitizing activity as well as radioprotective and chemoprotective properties [12,13]; the molecule is under investigation as a tumor priming agent in an open-label phase II clinical trial called TRIPLE THREAT (NCT02489903), which involves treatment of SCLC, non-small-cell lung cancer (NSCLC) or platinum-refractory neuroendocrine tumors with RRx-001 until progression followed by sequential re-introduction of cisplatin or carboplatin and etoposide. In this report, the case of 77-year-old Caucasian male with extensive-stage refractory SCLC - so categorized because he initially relapsed during ongoing first-line treatment - who responded to retreatment with carboplatin/ etoposide after progression on RRx-001 monotherapy is presented.

\section{Case Presentation}

A 77-year-old Caucasian male with a 30-pack-year smoking history was diagnosed with a medically operable stage 1 NSCLC (squamous cell carcinoma) in 2000 and 2007, resulting in left upper and right upper lobectomies. In 2009 a CT revealed a new pulmonary nodule for which he received radiation and 7 cycles of adjuvant carboplatin and taxol. In 2015 a new mass on CT scan, biopsied with fine needle aspiration and fiberoptic bronchoscopy, established a histological diagnosis of SCLC.

In May and July 2015 the patient completed 4 cycles of cisplatin-etoposide with response assessment every 2 cycles or 6 weeks. Despite a partial radiographic response at week 6, disease progression was observed on therapy during cycle 4 (week 12), which classified his disease as refractory. In November 2015 he was enrolled on the TRIPLE THREAT clinical trial and began weekly intravenous treatment with RRx-001. However, despite a marked symptomatic improvement, a restaging scan at week 6 demonstrated disease progression per RECIST v.1.1 which was suspicious for pseudoprogression [14], given the association of RRx-001 with transient tumor enlargement during initial scans followed by stabilization or shrinkage.

Nevertheless, on the basis of RECIST-defined progression, he was restarted on platinum doublets (carboplatin/etoposide) in December 2015. After 2 cycles of doublet therapy (week 6), which was much better tolerated on this occasion than the first time he received it, a CT scan demonstrated around 30\% tumor shrinkage, which met the criteria for a partial re- 
Carter et al.: Partial Response in an RRx-001-Primed Patient with Refractory Small-Cell Lung Cancer after a Third Introduction of Platinum Doublets

sponse. By week 12 (4 cycles) he developed neutropenia and therapy was interrupted. However, the restaging scan demonstrated a $58 \%$ reduction in the size of his tumors, confirming the partial response (fig. 1).

\section{Conclusion}

In the pantheon of the most difficult to treat metastatic malignancies, SCLC is on par with ovarian, brain, liver and pancreatic cancer in terms of its multidrug resistance [15] and consequent intractability to second-line therapies, including so-called targeted agents. Stagnant for more than three decades, the standard treatment for extensive-stage SCLC remains cisplatin and etoposide (PE); the exquisite initial chemosensitivity to PE belies the very poor prognosis after treatment with subsequent therapies. Even though PD-1 checkpoint inhibitors may be poised to challenge the platinum hegemony and change the treatment landscape in SCLC as in NSCLC, the response rates to pembrolizumab in the phase Ib KEYNOTE-028 trial [16] as well as nivolumab and nivolumab/ipilimumab in the phase I/II CheckMate 032 trial are counterbalanced by concerns about increased autoimmune toxicities [17], given the association between SCLC and paraneoplastic disorders such as Lambert-Eaton myasthenic syndrome.

A key oncologic treatment goal is to reverse the inevitable death trajectory of metastatic tumors to one of long-term survival while minimizing adverse effects. The promising strategy of episensitization $[18,19]$, a hybrid term coined by Oronsky, Carter, Scicinski and Reid, which involves priming with a systemically non-toxic epigenetic agent like RRx-001 followed by rechallenge with formerly tried chemotherapies, represents a literal comeback both for the patient if the strategy is successful and the re-introduced first-line treatment. To date, 2 out of 3 resistant/refractory SCLC patients enrolled in the TRIPLE THREAT trial have demonstrated responses to re-introduced platinum doublets, suggesting that the episensitization strategy may have the potential to yield promising clinical benefits.

\section{Statement of Ethics}

The patient described in this case report has given his informed consent as part of the TRIPLE THREAT clinical study (NCT02489903). This study protocol has been approved by the Walter Reed National Military Medical Center Institutional Review Board and the study conducted according to the Declaration of Helsinki principles. The patient gave written informed consent.

\section{Disclosure Statement}

B.O., J.S. and S.C. are employees of EpicentRx, Inc. EpicentRx, Inc. provided funding for the study.

\section{References}

1 Abidin AZ, Garassino MC, Califano R, Harle A, Blackhall F: Targeted therapies in small cell lung cancer: a review. Ther Adv Med Oncol 2010;2:25-37. 


\section{Case Reports in Oncology}

\begin{tabular}{l|l}
\hline Case Rep Oncol 2016;9:285-289 \\
\hline DOI: 10.1159/000446209 & $\begin{array}{l}\text { (c) 2016 The Author(s). Published by S. Karger AG, Basel } \\
\text { www.karger.com/cro }\end{array}$ \\
\hline
\end{tabular}

Carter et al.: Partial Response in an RRx-001-Primed Patient with Refractory Small-Cell Lung Cancer after a Third Introduction of Platinum Doublets

2 Spigel DR: Treatment update in small-cell lung cancer: from limited to extensive disease. Curr Treat Options Oncol 2012;13:505-515.

3 Hurwitz JL, McCoy F, Scullin P, Fennell DA: New advances in the second-line treatment of small cell lung cancer. Oncologist 2009;14:986-994.

4 Demedts IK, Vermaelen KY, van Meerbeeck JP: Treatment of extensive-stage small cell lung carcinoma: current status and future prospects. Eur Respir J 2010;35:202-215.

5 Jotte R, Conkling P, Reynolds C, Galsky MD, Klein L, Fitzgibbons JF, et al: Randomized phase II trial of singleagent amrubicin or topotecan as second-line treatment in patients with small-cell lung cancer sensitive to first-line platinum-based chemotherapy. J Clin Oncol 2011;29:287-293.

-6 Kaira K, Sunaga N, Tomizawa Y, Yanagitani N, Shimizu K, Imai H, et al: A phase II study of amrubicin, a synthetic 9-aminoanthracycline, in patients with previously treated lung cancer. Lung Cancer 2010;69:99104.

7 von Pawel J, Jotte R, Spigel DR, O’Brien ME, Socinski MA, Mezger J, et al: Randomized phase III trial of amrubicin versus topotecan as second-line treatment for patients with small-cell lung cancer. J Clin Oncol 2014;32:4012-4019.

8 Huber RM, Reck M, Gosse H, von Pawel J, Mezger J, Saal JG, et al: Efficacy of a toxicity-adjusted topotecan therapy in recurrent small cell lung cancer. Eur Respir J 2006;27:1183-1189.

-9 von Pawel J, Schiller JH, Shepherd FA, Fields SZ, Kleisbauer JP, Chrysson NG, et al: Topotecan versus cyclophosphamide, doxorubicin, and vincristine for the treatment of recurrent small-cell lung cancer. J Clin Oncol 1999;17:658-667.

10 Reid T, Oronsky B, Scicinski J, Scribner CL, Knox SJ, Ning S, et al: Safety and activity of RRx-001 in patients with advanced cancer: a first-in-human, open-label, dose-escalation phase 1 study. Lancet Oncol $2015 ; 16: 1133-1142$.

11 Zhao H, Ning S, Scicinski J, Oronsky B, Knox SJ, Peehl DM: Epigenetic effects of RRx-001: a possible unifying mechanism of anticancer activity. Oncotarget 2015;6:43172-43181.

12 Scicinski J, Oronsky B, Ning S, Knox S, Peehl D, Kim MM, et al: NO to cancer: The complex and multifaceted role of nitric oxide and the epigenetic nitric oxide donor, RRx-001. Redox Biol 2015;6:1-8.

13 Oronsky B, Scicinski J, Ning S, Peehl D, Oronsky A, Cabrales P, et al: RRx-001, a novel dinitroazetidine radiosensitizer. Invest New Drugs 2016, Epub ahead of print.

14 Carter C, Schmitz B, Peterson P, Quinn M, Degesys A, Jenkins J, et al: Immune reactivity and pseudoprogression or tumor flare in a serially biopsied neuroendocrine patient treated with the epigenetic agent RRx-001. Case Rep Oncol 2016;9:164-170.

15 Pleasance ED, Stephens PJ, O'Meara S, McBride DJ, Meynert A, Jones D, et al: A small-cell lung cancer genome with complex signatures of tobacco exposure. Nature 2010;463:184-190.

16 Ott PA, Elez Fernandez E, Hiret S, Kim DWM, Rebecca A, Winser T, Saraf S, et al: Pembrolizumab for ED SCLC: efficacy and relationship with PD-L1 expression. 16th World Conference on Lung Cancer, 2015, Denver, CO, abstract 3285.

17 Calvo E, López-Martin JA, Bendell J, Eder JP, Taylor M, Ott PA, et al: 3098 nivolumab (NIVO) monotherapy or in combination with ipilimumab (IPI) for treatment of recurrent small cell lung cancer (SCLC). Eur J Can cer 2015;51:S633.

$>18$ Oronsky BT, Oronsky AL, Lybeck M, Oronsky NC, Scicinski JJ, Carter C, et al: Episensitization: defying time’s arrow. Front Oncol 2015;5:134.

19 Oronsky B, Oronsky N, Knox S, Fanger G, Scicinski J: Episensitization: therapeutic tumor resensitization by epigenetic agents: a review and reassessment. Anticancer Agents Med Chem 2014;14:1121-1127. 


\section{Case Reports in Oncology}
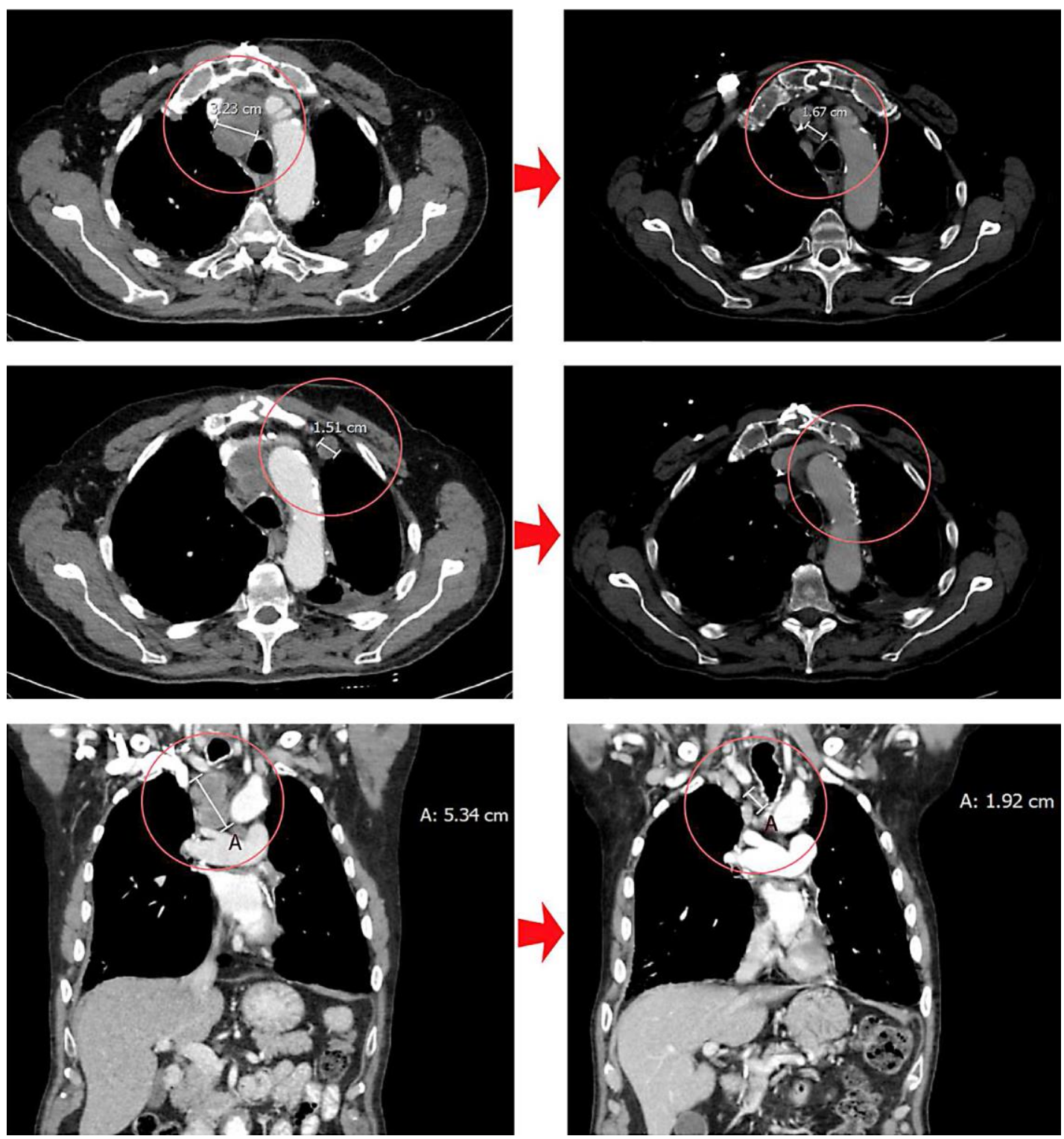

Fig. 1. CT scan images showing tumor shrinkage after re-exposure to platinum doublets. Left: At disease progression on the study drug RRx-001, prior to re-introduction of platinum (12/30/2015). Right: After 4 cycles of platinum therapy (carboplatin/etoposide) (4/6/2016). Upper row: Decrease in size of the paratracheal lesion from 3.23 to $1.67 \mathrm{~cm}(-48 \%)$. Middle row: Disappearance of the right upper lobe lymph node lesion. Lower row: Decrease in size of the subtracheal lesion from 5.34 to $1.92 \mathrm{~cm}(-64 \%)$. 